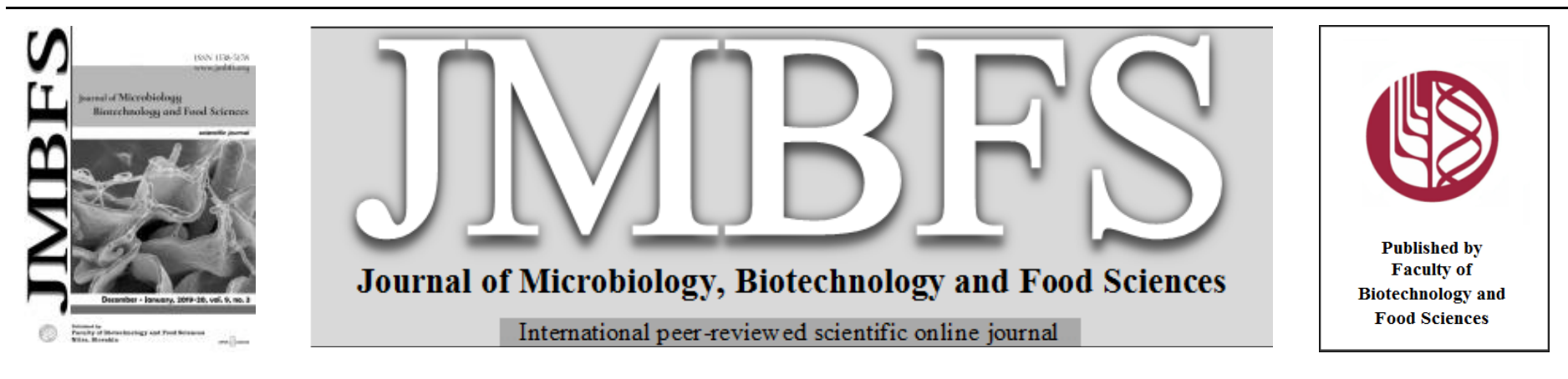

\title{
COMPARISON OF PHENOLIC CONTENT IN CABERNET SAUVIGNON AND SAPERAVI WINES
}

\author{
Shyngys Sergazy ${ }^{l}$, Alexandr Gulyayev ${ }^{I}$, Galina Dudikova ${ }^{2}$, Laura Chulenbayeva ${ }^{1}$, Madiyar Nurgaziyev ${ }^{l}$, Krivyh Elena $^{3}$, Ayaulym \\ Nurgozhoina ${ }^{l}$, Arailym Ziyat ${ }^{l}$, Vladislav Tritek ${ }^{l}$, Samat Kozhakhmetov ${ }^{l}$, Almagul Kushugulova ${ }^{l}$
}

\begin{abstract}
Address(es):
${ }^{1}$ PI "National Laboratory of Astana”, Nazarbayev University, Astana, Kazakhstan.

${ }^{2}$ Kazakh Research Institute of Processing and Food Industry, Almaty, Kazakhstan.

${ }^{3}$ Khanty-Mansiysk State Medical Academy, Khanty-Mansiysk, Russian Federation.

*Corresponding author: shynggys.sergazy@nu.edu.kz, laura.chulenbayeva@nu.edu.kz
\end{abstract}

doi: $10.15414 / j m b f s .2019 / 20.9 .3 .557-561$

ARTICLE INFO

Received 5. 3. 2019

Revised 30. 5. 2019

Accepted 5. 6. 2019

Published 1. 12. 2019

Regular article

open $O$ access

\begin{abstract}
Several studies reveal that the phenolic compounds present in the wine and their concentrations determine physiological activities of the red wine. In this study, the main polyphenol components, including hydroxycinnamic acids, flavones, flavan-3-ols and stilbenoids, were investigated via HLPC-UV in the "Cabernet Sauvignon" and "Saperavi" wines selected from different regions and different years. In assistance of a meta-analysis, we found that there are no fundamental differences in phenolic compounds between the wines Cabernet Sauvignon and Saperavi. However, the amounts of several important phenolic materials such as catechin, caffeic acid, p-coumaric acid, chlorogenic acid and myricetin significantly higher in Saperavi wine as compared to Cabernet Sauvignon. Moreover, on the basis of the correlation analysis, we assume that flavones synthesis and regulation of stilbenoids coordinated to a greater extent in "Saperavi" than in "Cabernet Sauvignon".
\end{abstract}

Keywords: phenolic compounds, red wine, Cabernet Sauvignon, Saperavi, HPLC-UV

\section{INTRODUCTION}

Recently, there is a decreasing tendency of alcohol consumption. According to International Agency for Research on Cancer and World Health Organization (IARC-WHO), alcohol and acetaldehyde have a carcinogenic effect (IARC, 2010, 2012). Therefore in 2010 , the WHO adopted a Global Strategy to reduce the harmful use of alcohol (WHO, 2010). They aimed to decrease the alcohol consumption by $10 \%$ in 2025 , and some progress has been achieved by now (WHO, 2010). Grape wine is an attribute of the traditional feast in some countries and it is a rich source of biologically active substances. Hundreds of articles have been published, showing the multiple potentially beneficial properties of polyphenols of wine (Chiva-Blanch at al., 2013; Friedman, 2014; Biasi at al., 2014). Despite this, there is no evidence, fully meet all the criteria of evidence-based medicine that red wine reduces oxidative stress in humans (Covas at al., 2010). It is possible that alcohol, a natural component of wine, is the cause of conflict in the experimental data and the results of epidemiological studies. That is the conclusion led the study of the relationship between the content of polyphenols in the diet and the risk of breast cancer (Touvier at al. 2013). High levels of dietary hydroxybenzoic acids, flavones, flavonols, catechins, theaflavins and pro anti-cyanide are associated with a low risk of developing the disease, but only for those women who consumed less than $6.5 \mathrm{~g}$ of alcohol per day. In contrary, women with higher consumption of alcohol, hydroxybenzoic acids, flavones, anthocyanins, catechins and pro anti-cyanide are associated with the risk of breast cancer. Thus, it seems that alcohol is not only carcinogenic by itself, but also contributes to the modulation anticarcinogenic properties of polyphenols in procarcinogens. The most obvious challenge facing the oenology is to produce from traditional wine a new dietary supplement - a soft drink with an optimal composition for the prevention of malignant tumors, cardiovascular diseases, diabetes, intestinal and neurodegenerative diseases. One of the key ways to address these problems is to know variations in the composition of polyphenols of grape wines and their impact on human health. In this regard, the question about fundamental differences in the composition of the polyphenols of red wines produced from grapes of different species has to be investigated. In the present study, we compared the two age-old technical grape varieties, the Cabernet Sauvignon, one of the most famous in the world of grapes, and the Saperavi, another well-known species among the world assortment of red grape (Ketskhoveli at al., 2012). The analysis could be carried out by directly comparing the composition of the extracts from the berries or the composition of the wine of the harvest, but bearing in mind significant variability in the content of polyphenols, depending on the conditions of growth and maturation, we anazed several samples of wines from different years and harvest different regions to provide a balanced assessment of the potential of these varieties.

\section{MATERIALS AND METHODS}

\section{Wine samples}

Wines from different manufacturers harvested in 2009-2012 have been obtained from the market stocks (Table 1). Samples were opened, protected against sunlight and stored at $4^{\circ} \mathrm{C}$. Analyses were carried out within 3 days. Each wine was analyzed 1 time.

\section{Reagents}

Formic acid, acetonitrile, ethanol and chromatographic standard set $((+)$-catechin, (-)-epicatechin, gallic acid, trans-caffeic acid, trans-p-coumaric acid, transferulic acid, chlorogenic acid, quercetindehydrate, myricetin, kaempferol, $( \pm$ ) naringenin, resveratrol, polydatin) was from Sigma-Aldrich.

\section{HPLC analysis}

Analysis was conducted polyphenols content by HPLC using the Agilent 1290 chromatograph Infinity. The separation was carried out in a gradient mode on ZORBAXRRHDSB-C18 column $2.1 \times 100 \mathrm{~mm}, 1.8 \mathrm{~mm}$. The mobile phase consisted of A: $0.1 \%$ aqueous solution of formic acid B: acetonitrile containing formic acid at a concentration of $0.1 \%$. The gradient was carried out in the following sequence:

$\begin{array}{lllllllll}\mathrm{t}, \min & 0 & 5 & 10 & 25 & 26 & 30 & 31 & 35 \\ \% \mathrm{~B} & 0 & 10 & 10 & 35 & 100 & 100 & 0 & 0\end{array}$

The flow rate is $0,3^{\circ} \mathrm{ml} / \mathrm{min}$ at $30^{\circ} \mathrm{C}$ (samples stored at $4^{\circ} \mathrm{S}$ in bottles of dark glass). Registration was carried out diode array detector at $280 \mathrm{~nm}$ and $325 \mathrm{~nm}$. For the analysis was used 31 of the sample.

Calibration solutions 
Resveratrol, myricetin, quercetin and kaempferol were dissolved in 96\% ethanol; the rest was dissolved in a mixture of standards of ethanol / water 50/50 to a concentration of $5 \mathrm{mg} / \mathrm{ml}$ and stored at $-20^{\circ} \mathrm{C}$. Working calibration mixtures were prepared with concentrations of $0.01 \mathrm{mg} / 1$ to $500 \mathrm{mg} / 1$

Table 1 The wine samples tested

\begin{tabular}{|c|c|c|c|c|c|}
\hline Wine samples & Grape variety & Year & $\mathrm{pH}$ & Alcohol content & Location \\
\hline 1 & Cabernet Sauvignon & $\begin{array}{l}2011(\mathrm{n}=3) \\
2012(\mathrm{n}=3) \\
2013(\mathrm{n}=2)\end{array}$ & $3.2-3.8$ & $11-13.5 \%$ & Chili $(n=8)$ \\
\hline 2 & Cabernet Sauvignon & $\begin{array}{l}2006 \\
2009(n=2) \\
2012(n=3) 2011(n=2)\end{array}$ & $3.2-3.8$ & $11-13.5 \%$ & France $(n=8)$ \\
\hline 3 & Cabernet Sauvignon & $\begin{array}{l}2011(\mathrm{n}=3) \\
2009(\mathrm{n}=3) \\
2012(\mathrm{n}=2)\end{array}$ & $3.2-3.8$ & $11-13.5 \%$ & Moldova $(\mathrm{n}=8)$ \\
\hline 5 & Cabernet Sauvignon & 2011 & $3.2-3.8$ & $11-13.5 \%$ & South Africa $(\mathrm{n}=1)$ \\
\hline 6 & Cabernet Sauvignon & 2011 & $3.2-3.8$ & $11-13.5 \%$ & Italy $(\mathrm{n}=1)$ \\
\hline 7 & Cabernet Sauvignon & 2010 & $3.2-3.8$ & $11-13.5 \%$ & Kazakhstan $(\mathrm{n}=1)$ \\
\hline 8 & Saperavi & $2007-2013$ & $3.2-3.8$ & $11-13.5 \%$ & Georgia $(n=29)$ \\
\hline & Saperavi & $2009(n=3)$ & $3.2-3.8$ & $11-13.5 \%$ & Kazakhstan $(\mathrm{n}=3)$ \\
\hline
\end{tabular}

\section{Statistical methods}

Test the hypothesis of normal distribution of data sets obtained and samples belong to the same population, and correlation analysis was performed using STATISTICA 8.0 StatSoft program. Composition of polyphenols between two types of wine samples was analyzed using nonparametric Mann-Whitney U-test (Ledermann at al., 1984).

\section{RESULTS AND DISCUSSION}

\section{The concentration of polyphenols}

Table 1 shows the minimum and maximum concentration of polyphenol found in the experimental wine samples. The resulting set of most of the polyphenols concentrations are not normally distributed, so the table shows the median values and the results of testing the hypothesis about the accessories one set of samples using the nonparametric Mann-Whitney U-test.

Table 1 Contents of certain polyphenol ( $\mathrm{mg} / \mathrm{L}$ ) in samples of wine.

\begin{tabular}{|c|c|c|c|c|c|c|c|}
\hline \multirow{2}{*}{$\begin{array}{l}\text { Wine } \\
\text { Polyphenols }\end{array}$} & \multicolumn{3}{|c|}{ Caberne Sauvignon $(\mathrm{n}=28)$} & \multicolumn{3}{|c|}{ Saperavi $(n=32)$} & \multirow{2}{*}{$\mathrm{p}_{\text {U-test Mann-Whitney }}$} \\
\hline & $\min$ & $\max$ & median & $\min$ & $\max$ & median & \\
\hline (-)-Epicatechin & 0,8 & 29,6 & 13,6 & 4,1 & 21,7 & 12,9 & 0,273 \\
\hline trans-Caffeic acid & 3,73 & 10,07 & 6,94 & 4,44 & 17,46 & 8,66 & 0,0002 \\
\hline trans-p-Coumaric acid & 1,16 & 7,69 & 3,27 & 1,04 & 11,12 & 4,61 & 0,047 \\
\hline trans-Ferulic acid & 0,22 & 3.81 & 0,67 & 0,00 & 3,19 & 0,83 & 0,993 \\
\hline Quercetin & 0,46 & 9,95 & 2,09 & 1,13 & 7,34 & 2,42 & 0,313 \\
\hline Myricetin & 0,02 & 5,60 & 0,95 & 0,46 & 8,55 & 2,69 & 0,012 \\
\hline Kaempferol & 0,00 & 0,85 & 0,03 & 0,01 & 0,64 & 0,05 & 0,330 \\
\hline$( \pm)$-Naringenin & 0,01 & 0,09 & 0,04 & 0,01 & 0,06 & 0,04 & 0,976 \\
\hline Resveratrol & 0,20 & 2,66 & 0,82 & 0,38 & 4,96 & 1,07 & 0,103 \\
\hline Polydatin & 0,75 & 9,18 & 3,51 & 1,08 & 6,41 & 3,99 & 0,293 \\
\hline
\end{tabular}

pU-test - the probability belong to the same set of concentrations of polyphenols in wines Cabernet Sauvignon and Saperavi by U-Mann-Whitney test.

As can be seen, significant differences were found in concentrations of catechin, caffeic, p-coumaric and chlorogenic acid, and myricetin. The most pronounced of these differences for caffeic acid and catechin. To what extent these differences are due to grape variety, and not, for example, the technology of preparation of wine? It is possible that our number of samples is not representative enough. The representativeness of our data on samples of Cabernet Sauvignon wines can be estimated using similar research results available in the literature. We used the information from the site Phenol-Explorer and add more information from several articles. The results obtained by the base analysis are presented in Table

First of all attention should be paid to the fact that our values of the concentrations of almost all materials are within ranges known from the literature. In two cases, namely, the minimum concentration of epicatechin and a pair of coumaric acid were lower than literature values, but those were the only observation. Next in order of importance were already above the minimum concentration of the border. In parentheses we note that the formal reason to remove these small values of our variational series we did not have. Thus, our estimates generally do not conflict with the combined data in the literature. The values of the probabilities given in the table correspond to the results of testing the hypothesis of a single set of accessories, we have obtained from the literature and well-known wine analysis Cabernet Sauvignon by U-Mann-Whitney (/ CS $\mathrm{pU}$ test). The significance of the differences on a number of parameters likely to be of natural differences of local climatic conditions prevailing in different years, as well as differences in the production technology. It must be admitted that we have not analyzed the composition of the best examples of Cabernet Sauvignon wine. However, it is now important that we estimate the concentration of catechin and caffeic acid in Cabernet Sauvignon not differ from the cumulative data of other research groups. In our view, this means that the application for a higher concentration of caffeic acid in wines Saperavi than Cabernet Sauvignon can be taken with confidence, even when compared with the published data (/ S pU test $=0.0315)$. Regarding the concentration of catechins such cannot be stated unconditionally. Note that a slight excess of the average concentration of caffeic acid in the order of magnitude smaller Saperavi range where there may be fluctuations in Cabernet Sauvignon. In addition, the assessment regarding the published data, the content of steam coumaric acid and myricetin in Cabernet Sauvignon and Saperavi from our sample wines go from low to be acceptable. In other words, in general, we can assume that potential, we investigated the composition of polyphenols, the wine produced from grapes Saperavi and Cabernet Sauvignon, are virtually indistinguishable. This conclusion may not be consistent with the opinion of some Georgian wine-makers who are confident of the advantages of traditional Kakheti wine production technologies (Shalashvili at al., 2011). We are aware that the community of our findings is limited by sample specimens Saperavi wine.

\section{Spearman's correlation coefficients}

The concentrations of phenolic compounds is obviously dependent. Gallic acid metabolites formed from shikimatnogo path leading to the synthesis of phenylalanine and tyrosine, which is formed from p-coumaric acid - a precursor of all other investigated here phenolic compounds (see Figure.). 
Table 2 Contents of certain polyphenol ( $\mathrm{mg} / \mathrm{L}$ ) in Cabernet Sauvignon wine samples from published sources.

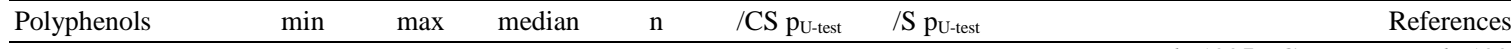

Frankel at al., 1995; Goldberg at al., 1998; Burns at al., 2000; Teissedre

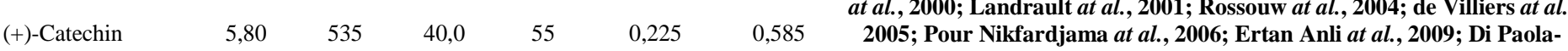

Naranjo at al., 2011; Li at al., 2011; Cáceres at al., 2012; Jiang at al.,

2012; Bai at al., 2013; Muccillo at al., 2014

\begin{tabular}{|c|c|c|c|c|c|c|c|}
\hline (-)-Epicatechin & 3,15 & 186 & 31,5 & 49 & $<0,0001$ & $<0,0001$ & $\begin{array}{l}\text { at al., 2000; Landrault at al., 2001; Rossouw at al., 2004; de Villiers at al. } \\
\text { 2005; Pour Nikfardjama at al., 2006; Ertan Anli at al., 2009; Di Paola- } \\
\text { Naranjo at al., 2011; Li at al., 2011; Jiang at al., 2012; Bai at al., 2013; } \\
\text { Muccillo at al., } 2014\end{array}$ \\
\hline
\end{tabular}
at al., 2000; Landrault at al., 2001; Rossouw at al., 2004; de Villiers at al., Muccillo at al., 2014

\begin{tabular}{lcccccc} 
Gallic acid & 15 & 126 & 35,6 & 40 & 0,737 & 0,468 \\
& & & & & & \\
\hline Caffeic acid & 2,02 & 30,0 & 6,95 & 36 & 0,588 & 0,031
\end{tabular}

ankel at al., 1995; Burns at al., 2000; Teissedre at al., 2000; Landrault at al., 2001; Rossouw at al., 2004; de Villiers at al., 2005; Pour

Nikfardjama at al., 2006; Ertan Anli at al., 2009; Di Paola-Naranjo at al., 2011; Li at al., 2011; Bai at al., 2013; Kilinc at al., 2003; Gambelli at al., 2004

Frankel at al., 1995; Burns at al., 2000; Teissedre at al., 2000; Landrault at al., 2001; Rossouw at al., 2004; de Villiers at al., 2005; Pour Nikfardjama at al., 2006; Di Paola-Naranjo at al., 2011; Li at al., 2011; Bai at al., 2013; Gambelli at al., 2004

Burns at al., 2000; Teissedre at al., 2000; Rossouw at al., 2004; de Villiers at al., 2005; Pour Nikfardjama at al., 2006; Di Paola-Naranjo at al., 2011; p-Coumaric acid $\quad 1,30 \quad 21,6 \quad 4,80 \quad 24 \quad 0,0008 \quad 0,112$ Bai at al., 2013; Kilinc at al., 2003; Gambelli at al., 2004; Goldberg at al., 1998

\begin{tabular}{llllllll}
\hline Ferulic acid & 0,00 & 4,00 & 0,30 & 6 & 0,288 & 0,297 & $\begin{array}{c}\text { de Villiers at al., 2005; Pour Nikfardjama at al., 2006; Di Paola-Naranjo } \\
\text { at al., 2011; Kilinc at al., 2003 }\end{array}$
\end{tabular}

\begin{tabular}{|c|c|c|c|c|c|c|c|}
\hline Quercetin & 0,00 & 23,0 & 3,20 & 63 & 0,439 & 0,644 & $\begin{array}{c}\text { Frankel at al., 1995; Burns at al., 2000; Rossouw at al., 2004; de Villiers } \\
\text { at al., 2005; Pour Nikfardjama at al., 2006; Di Paola-Naranjo at al., } \\
\text { 2011; Li at al., 2011; Bai at al., 2013; Muccillo at al., 2014; Goldberg at } \\
\text { al., 1998; McDonald at al., 1998; Tsanova-Savova at al., 2002; Fang at al., } \\
\text { 2007 }\end{array}$ \\
\hline Myricetin & 0,00 & 17,9 & 3,20 & 53 & 0,0002 & 0,155 & $\begin{array}{l}\text { Frankel } \text { at al., 1995; Burns at al., 2000; Rossouw at al., 2004; de Villiers } \\
\text { at al., 2005; Di Paola-Naranjo at al., 2011; Li at al., 2011; Bai } \text { at al., 2013; } \\
\text { McDonald at al., 1998; Tsanova-Savova at al., 2002; Fang at al., 2007 }\end{array}$ \\
\hline Kaempferol & 0,00 & 3,53 & 0,20 & 27 & 0,006 & 0,003 & $\begin{array}{l}\text { Burns at al., 2000; Rossouw at al., 2004; de Villiers at al., 2005; Di Paola- } \\
\text { Naranjo at al., 2011; Li at al., 2011; Bai at al., 2013; Tsanova-Savova at } \\
\text { al., 2002; Fang at al., 2007 }\end{array}$ \\
\hline
\end{tabular}
al., 2002; Fang at al., 2007

\begin{tabular}{|c|c|c|c|}
\hline Resveratrol & 0,00 & 15,2 & 1,30 \\
\hline
\end{tabular}

Frankel at al., 1995; de Villiers at al., 2005; Pour Nikfardjama at al., 2006; Di Paola-Naranjo at al., 2011; Li at al., 2011; Bai at al., 2013; Muccillo at al., 2014; Gambelli at al., 2004; Lamuela-Raventos at al., 1995; Goldberg at al., 1996; Lamikanra at al., 1996; Mozzon at al., 1996; Sato at al., 1997; Gu at al., 1999; Abril at al., 2005; Vitrac at al., 2005

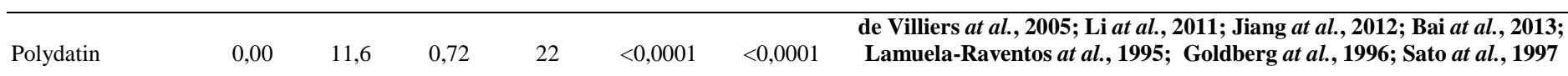

CS pU-test - the probability belong to the same set of concentrations of polyphenols in wines Cabernet Sauvignon from the literature and our results on the U-MannWhitney test. /S pU-test - the probability belong to the same set of concentrations of polyphenols in wines Cabernet Sauvignon from the literature and the results of our analysis of the wine Saperavi by U-Mann-Whitney test.

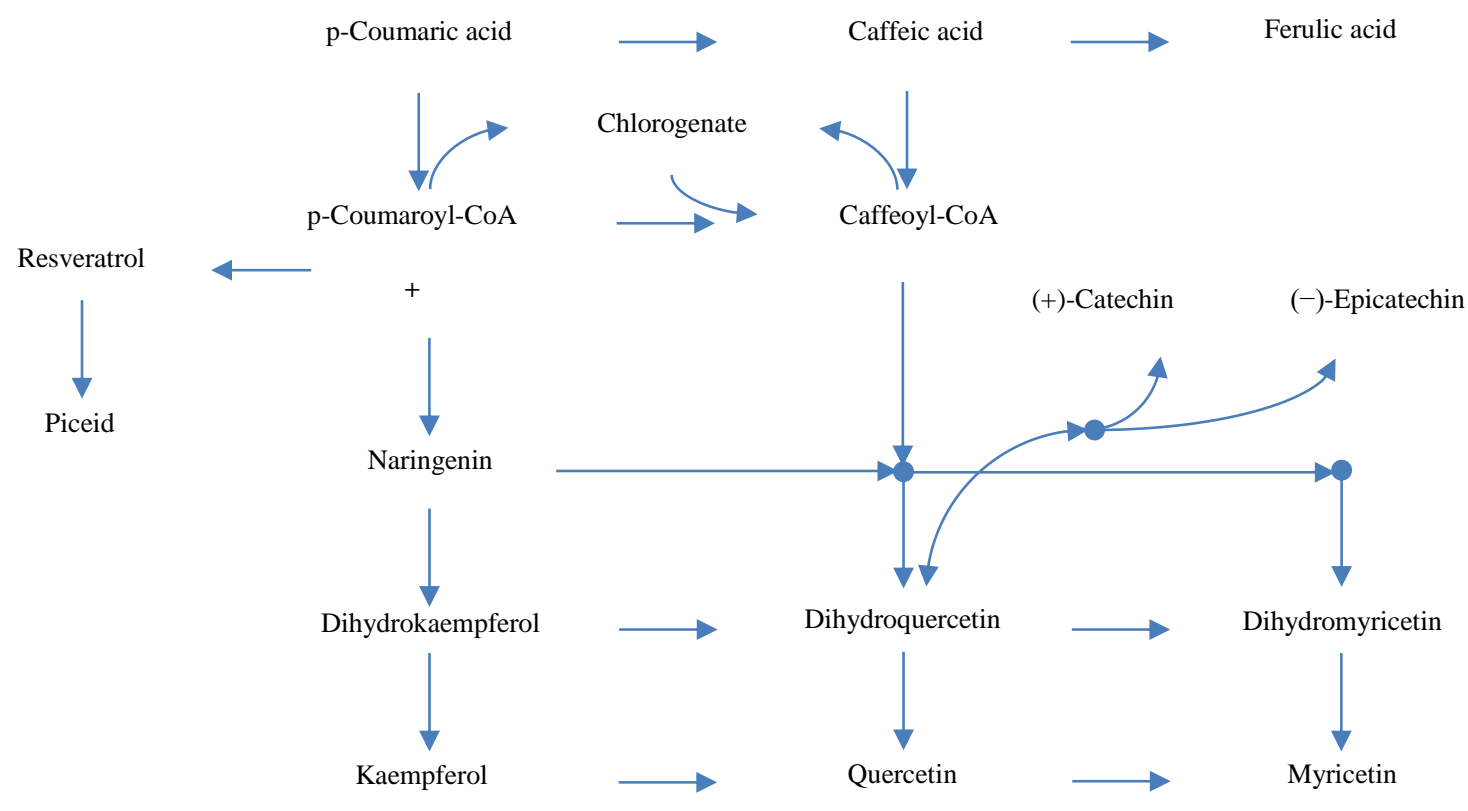

Figure 1 Scheme of metabolic relationships between investigated (poly) phenols (For simplicity, many intermediary metabolites omitted) 
Communications between the concentrations of polyphenols indicators are presented in Table 3 above are arranged diagonally Spearman's correlation coefficients obtained in the analysis of wines Cabernet Sauvignon, below the diagonal - Saperavi. It can be seen that there are the same type as the connection between the concentrations of polyphenols, and different in magnitude and even direction. Table 4 (above the diagonal) are united by the correlation coefficients of variation series, which clearly identifies the common features of the two types of wine. Grade-specific linkages are represented as differences of correlation coefficients (diagonally below in Table 4). Noteworthy positive correlation in pairs of p-coumaric acid - resveratrol and p-coumaric acid - naringenin and negative correlation of p-coumaric acid and ferulic acid occurring Saperavi wines but not in Cabernet Sauvignon. For Saperavi are also characterized by a close relationship between the concentrations of flavonols and catechins.

Table 3 Spearman's correlation coefficients for wines Cabernet Sauvignon (rS1, above the diagonal) and Saperavi (rS2, below the diagonal). Statistically significant (p $<0,05)$ coefficients in bold

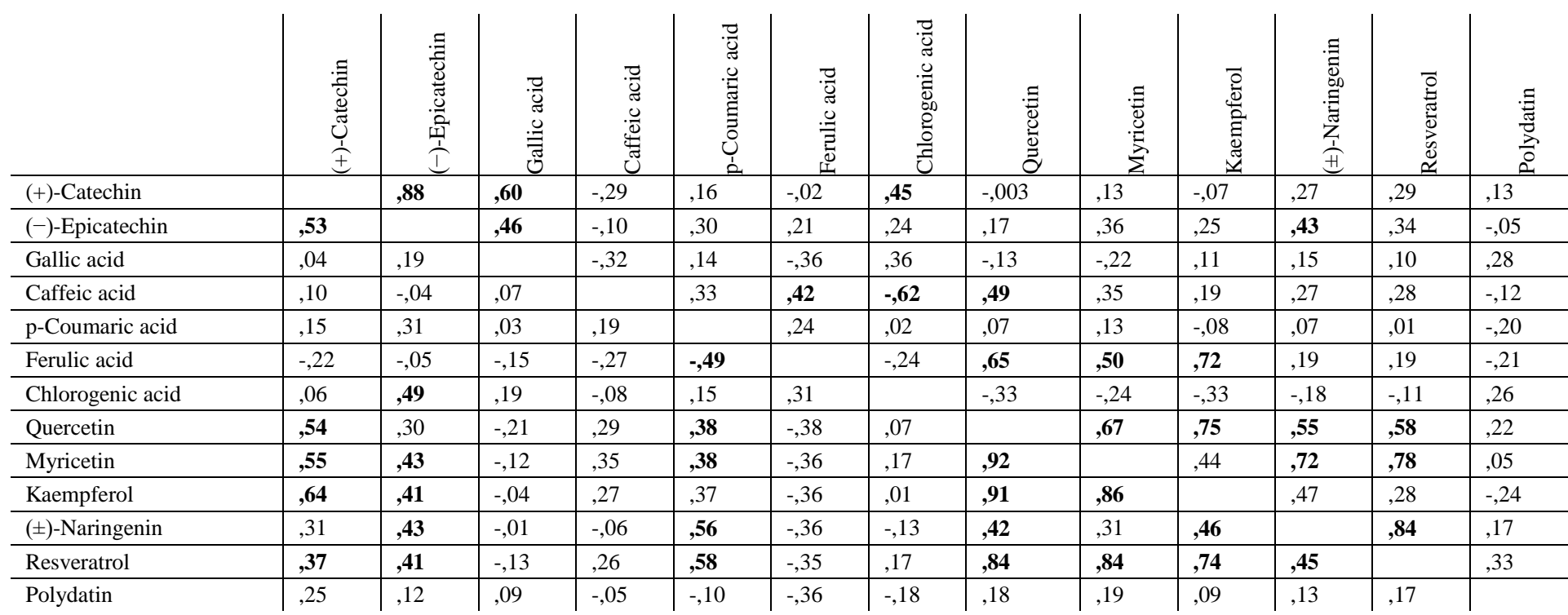

These differences are the links between concentrations of phenolic compounds in wines suggest that the regulation of metabolism in grapes of different varieties has its own characteristics. This is confirmed, for example, direct studies of the composition of extracts of peel and expression of relevant genes grape varieties Cabernet Sauvignon and Shiraz in the course of maturation [43]. Furthermore, in the production of wine and its aging processes occur which lead to a change in its composition. Thus, the structure of the various relations of phenolic compounds in the final product is the result of various factors set action. Nevertheless, the relationship between phenolic compounds in some of the key points of metabolism observed in wines Saperavi, you can probably be regarded as a reflection of the relatively more rigid coordination of metabolic pathways from the Saperavi grape variety than that of Cabernet Sauvignon.

Table 4 Spearman correlation coefficients for common wines Cabernet Sauvignon and Saperavi (above the diagonal) and the difference rS1-rS2 (below the diagonal, represented only a statistically significant $(\mathrm{p}<0,05)$ difference).

\begin{tabular}{|c|c|c|c|c|c|c|c|c|c|c|c|c|c|}
\hline & 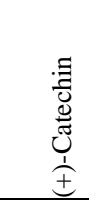 & 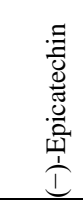 & 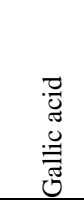 & 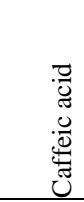 & 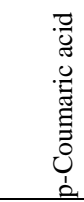 & 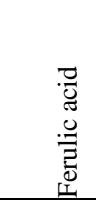 & 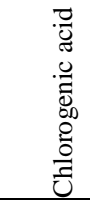 & 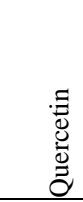 & 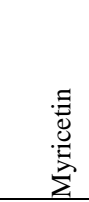 & 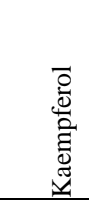 & 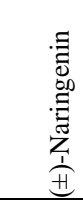 & 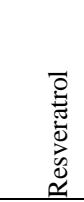 & 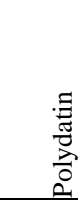 \\
\hline (+)-Catechin & & ,59 & ,21 &, 12 &, 25 &,- 07 &, 42 & ,24 &, 38 & ,36 & ,26 & ,39 & ,30 \\
\hline (-)-Epicatechin &, 35 & & ,37 &,- 12 & ,27 &, 12 & ,29 & ,20 & ,31 & ,33 &, 42 & ,35 & ,03 \\
\hline Gallic acid & 57 & & &,- 18 & 07 &,- 24 & ,14 &,- 21 &,- 21 &, 00 &, 08 &,- 05 &, 12 \\
\hline Ferulic acid & & & & 69 & ,73 & &,- 01 & ,27 &, 16 &, 06 &,- 06 &,- 03 &,- 26 \\
\hline Chlorogenic acid & & & &,- 54 & & & &,- 01 & ,17 &,- 05 &,- 15 &, 15 & ,07 \\
\hline Quercetin &,- 54 & & & & & 1,02 & & & ,77 & ,79 &, 54 & ,70 & , 16 \\
\hline Myricetin & & & & & &, 86 & &,- 25 & & ,68 &, 53 &, 81 &, 13 \\
\hline Kaempferol &,- 71 & & & & & 1,08 & & &,- 42 & &, 49 &, 56 &,- 03 \\
\hline
\end{tabular}

\section{CONCLUSION}

In the present work, we report the investigation and comparison on major phenolic compounds and concentrations of two types of wine samples, the "Cabernet Sauvignon" and the "Saperavi" wines.

The study of the phenolic compounds of Cabernet Sauvignon and Saperavi wines has shown that there are no fundamental differences in the variety of phenolic compounds between the two types of wines. However, the concentrations of several important phenolic materials such as catechin, caffeic acid, p-coumaric acid, chlorogenic acid and myricetin significantly higher in Saperavi wine as compared to Cabernet Sauvignon, whereas, non-significant differences were noticed in the concentration of hydroxycinnamic acids, flavonols, flavan-3-ols and stilbenoids. Correlation analysis of Cabernet Sauvignon and Saperavi wines between the studied components presumably reflect a more rigid coordination of metabolism in the synthesis of flavonols and stilbenoids from Saperavi grape variety.

Acknowledgments: This work was supported by the grants from the Ministry of Education and Science of the Republic of Kazakhstan (BR05236508). 


\section{REFERENCES}

IARC (2010). Alcohol consumption and ethyl carbamate. IARC Monogr. Eval. Carcinog. Risks Hum, 96, 1-1428.

IARC (2012). Consumption of Alcoholic Beverages. Personal Habits and Indoor Combustions. IARC Monogr. Eval. Carcinog. Risks. Hum. 100E, 373-499.

WHO (2010). Global strategy to reduce harmful use of alcohol. World Health Organization

WHO (2010). Global status report on alcohol and health. - 2014 ed. World Health Organization.

Chiva-Blanch, G., Arranz, S., Lamuela-Raventos, R. \& Estruch R (2013). Effects of Wine, Alcohol and Polyphenols on Cardiovascular Disease Risk Factors: Evidences from Human Studies. Alcohol and Alcoholism. 48(3), 270-277. https://doi.org/10.1093/alcalc/agt007

Friedman, M. (2014). Antibacterial, Antiviral, and Antifungal Properties of Wines and Winery Byproducts in Relation to Their Flavonoid Content. Journa of Agricultural and Food Chemistry. 62, 6025-6042. https://doi.org/10.1021/jf501266s

Biasi, F., Deiana, M., Guina, T., Gamba, P., Leonarduzzi, G. \& Poli, G. (2014) Wine consumption and intestinal redox homeostasis. Redox Biology. 2014, Vol. 2, pp. 795-802. https://doi.org/10.1016/j.redox.2014.06.008

Covas, M., Gambert, P., Fitó, M. \& de la Torre, R. (2010). Wine and oxidative stress: Up-to-date evidence of the effects of moderate wine consumption on oxidative damage in humans. Atherosclerosis. 2010, Vol. 208, pp. 297-304 https://doi.org/10.1016/j.atherosclerosis.2009.06.031

Touvier, M., Druesne-Pecollo, N., Kesse-Guyot, E., Andreeva, V., Fezeu, L. Galan, P., Hercberg, S. \& Latino-Martel, P. (2013) Dual association between polyphenol intake and breast cancer risk according to alcohol consumption level: a prospective cohort study. Breast Cancer Res. Treat. 137, 225-236. https://doi.org/10.1007/s10549-012-2323-y

Ketskhoveli, N., Ramishvili, M. \& Tabidze, D. (2012). Georgian Ampelography. Tbilisi: Exclusive Print Plus. Georgia, 456.

Ledermann, W., chief ed. Handbook of applicable mathematics. Vol. VI Part A. Statistics. Lloyd E., ed. John Wiley \& Sons Ltd. Chichester, New York 1984, 580 p. ISBN 0-471-90274-8

Frankel, E., Waterhouse, A. \& Teissedre, P. (1995). Principal phenolic phytochemicals in selected California wines and their antioxidant activity in inhibiting oxidation of human low-density lipoproteins. Journal of Agricultural and Food Chemistry. 43, 890-894. https://doi.org/10.1021/jf00052a008

Goldberg, D., Karumanchiri, A., Tsang, E. \& Soleas, G. (1998). Catechin and epicatechin concentrations of red wines: regional and cultivar-related differences. American Journal of Enology and Viticulture. 49, 23-34.

Burns, J., Gardner, P., O'Neil, J., Crawford, S., Morecroft, I., McPhail, D., Lister, C., Matthews, D., MacLean, M., Lean, M., Duthie, G. \& Crozier, A. (2000) Relationship among antioxidant activity, vasodilation capacity, and phenolic content of red wines. Journal of Agricultural and Food Chemistry. 48, 220-230. https://doi.org/10.1021/jf9909757

Teissedre, P. \& Landrault, N. (2000). Wine phenolics: contribution to dietary intake and bioavailability. Food Research International. 33, 461-467. https://doi.org/10.1016/S0963-9969(00)00070-3

Landrault, N., Poucheret P., Ravel, P., Gasc, F., Cros, G. \& Teissedre, P. (2001) Antioxidant capacities and phenolics levels of French wines from differen varieties and vintages. J. Agric. Food Chem. 49, 3341-3348. http://dx.doi.org/10.1021/jf010128f

Rossouw, M. \& Marais, J. (2004). The phenolic composition of South African Pinotage, Shiraz and Cabernet Sauvignon wines. South African Journal of Enology and Viticulture. 25, 94-104. https://doi.org/10.21548/25-2-2143

de Villiers, A., Majek, P., Lynen, F., Crouch, A., Lauer, H. \& Sandra, P. (2005) Classification of South African red and white wines according to grape variety based on the non-coloured phenolic content. Eur. Food Res. Technol.221, 520 528. http://dx.doi.org/10.1007/s00217-005-1169-5

Pour Nikfardjama, M., Márk, L., Avar, P., Figler, M. \& Ohmacht, R. (2006) Polyphenols, anthocyanins, and trans-resveratrol in red wines. Food Chemistry. 98, 453-462. https://doi.org/10.1016/j.foodchem.2005.06.014

Ertan Anli, R. \& Vural, N. (2009). Antioxidant phenolic substances of Turkish red wines from different wine regions. Molecules. 14, 289297. https://doi.org/10.3390/molecules14010289

Di Paola-Naranjo, R., Baroni, M., Podio, N,., Rubinstein, H., Fabani, M., Badini, R., Inga, M., Ostera, H., Cagnoni, M., Gallegos, E., Gautier, E., Peral-Garcia, P., Hoogewerff, J. \& Wunderlin, D. (2011). Fingerprints for main varieties of argentinean wines: terroir differentiation by inorganic, organic, and stable isotopic analyses coupled to chemometrics. J Agric. Food Chem. 59(14), 7854 7865. https://doi.org/10.1021/jf2007419

Li, Z., Pan, Q., Jin, Z., Mu, L. \& Duan, C. (2011). Comparison on phenolic compounds in Vitis vinifera cv. Cabernet Sauvignon wines from five winegrowing regions in China. Food Chemistry. 125, 77-83. https://doi.org/10.1016/j.foodchem.2010.08.039

Cáceres, A.,; Peña-Neira, Á., Galvez, A., Obreque-Slier, E., López-Solís, R. \& Canals, J. (2012). Phenolic Compositions of Grapes and Wines from Cultivar Cabernet Sauvignon Produced in Chile and Their Relationship to Commercial
Value. Journal of Agricultural and Food Chemistry. 60, 8694-8702. https://doi.org/10.1021/jf301374t

Jiang, B. \& Zhang, Z-W. (2012). Comparison on phenolic compounds and antioxidant properties of cabernet sauvignon and merlot wines from four wine grape-growing regions in China. Molecules. 17(8), 8804-8821. https://doi.org/10.3390/molecules17088804

Bai, B., He, F., Yang, L., Chen, F., Reeves, M. \& Li, J. (2013). Comparative study of phenolic compounds in Cabernet Sauvignon wines made in traditional and Ganimede fermenters. Food Chem. 141, 3984-3992. https://doi.org/10.1016/j.foodchem.2013.06.074.

Muccillo, L., Gambuti, A., Frusciante, L., Iorizzo, M., Moio, L., Raieta, K. Rinaldi, A., Colantuoni, V. \& Aversano, R. (2014). Biochemical features of native red wines and genetic diversity of the corresponding grape varieties from Campania region. Food Chem. 143, 506-513. https://doi.org/10.1016/j.foodchem.2013.07.133

Kilinc, E. \& Kalkan, H. (2003). High-performance liquid chromatographic determination of some phenolic acids of Turkish commercial wines: an electrochemical approach. Journal of Wine Research 2003, Vol. 14, pp. 17-23. https://doi.org/10.1080/0957126032000114982

Gambelli, L. \& Santaroni, G. (2004). Polyphenols content in some Italian red wines of different geographical origins. Journal of Food Composition and Analysis. 17, 613-618. https://doi.org/10.1016/i.jfca.2003.09.010

Goldberg, D., Tsang, E., Karumanchiri, A. \& Soleas, G. (1998). Quercetin and pcoumaric acid concentrations in commercial wines. American Journal of Enology and Viticulture. 1998, Vol. 49, pp. 142-151.

McDonald, M., Hughes, M., Burns, J., Lean M., Matthews, D. \& Crozier, A. (1998). Survey of the Free and Conjugated Myricetin and Quercetin Content of Red Wines of Different Geographical Origins. Journal of Agricultural and Food Chemistry. 46, 368-375. https://doi.org/10.1021/jf970677e

Tsanova-Savova, S. \& Ribarova, F. (2002). Free and conjugated myricetin, quercetin, and kaempferol in Bulgarian red wines. Journal of Food Composition and Analysis. 15, 639-645. https://doi.org/10.1006/jfca.2002.1099

Fang, F., Li, J-M., Pan, Q-H. \& Huang, W-D. (2007). Determination of red wine flovones by HPLC and effect of aging. Food Chemistry. 101, 428-433 https://doi.org/10.1016/j.foodchem.2005.12.036

Lamuela-Raventos, R., Romero-Perez, A., Waterhouse, A. \& de la TorreBoronat, M. (1995). Direct HPLC analysis of cis- and trans-resveratrol and piceid isomers in Spanish red Vitis vinifera wines. Journal of Agricultural and Food Chemistry. 43, 281-283. https://doi.org/10.1021/jf00050a003

Goldberg, D., Ng, E., Karumanchiri, A., Diamandis, E. \& Soleas G. (1996) Resveratrol glucosides are important components of commercial wines. American Journal of Enology and Viticulture. 47, 415-420.

Lamikanra, O., Grimm, C., Rodin J. \& Inyang, I. (1996). Hydroxylated stilbenes in selected American wines. Journal of Agricultural and Food Chemistry. 44 1111-1115. https://doi.org/10.1021/jf950274j

Mozzon, M., Frega, N. \& Pallotta, U. (1996). Resveratrol content in some Tuscan wines. Italian Journal of Food Science. 8, 145-152.

Sato, M., Suzuki, Y., Okuda, T. \& Yokotsuka K. (1997). Contents of resveratrol, piceid, and their isomers in commercially available wines made from grapes cultivated in Japan. Bioscience, Biotechnology and Biochemistry. 61, 1800-1805. https://doi.org/10.1271/bbb.61.1800

Gu, X., Creasy, L., Kester, A. \& Zeece, M. (1999). Capillary electrophoretic determination of resveratrol in wines. Journal of Agricultural and Food Chemistry. 47, 3223-3227. https://doi.org/10.1021/jf981211e

Melzoch, K., Filip, V., Buckiova, D., Hanzlikova, I. \& Smrdrkal, J. (2000) Resveratrol - occurrence in wine originating from Czech vineyard regions and effect on human health. Czech Journal of Food Science. 18, 35-40.

Abril, M., Negueruela, A., Perez, C., Juan T. \& Estopanan G. (2005). Preliminary study of resveratrol content in Aragon red and rose wines. Food Chemistry. 92 729-736. https://doi.org/10.1016/j.foodchem.2004.08.034

Vitrac, X., Bornet A., Vanderlinde, R., Valls, J., Richard, T., Delaunay, J.-C. Mérillon J.-M. \& Teissédre, P.-L. (2005). Determination of Stilbenes (-viniferin, trans-astringin, trans-piceid, cis- and trans-resveratrol, -viniferin) in Brazilian Wines. Journal of Agricultural and Food Chemistry. 53, 5664-5669. https://doi.org/10.1021/jf050122g

Shalashvili, A., Ugrekhelidze, D., Targamadze, I., Zambakhidze, N. \& Tsereteli, L. (2011). Phenolic Compounds and Antiradical Efficiency of Georgian (Kakhethian) Wines. Journal of Food Science and Engineering. 1(5), 361-365. Degu, A., Hochberg, U., Sikron, N., Venturini, L., Buson, G., Ghan, R., Plaschkes, I., Batushansky, A., Chalifa-Caspi, V., Mattivi, F., Delledonne, M., Pezzotti M., Rachmilevitch, S., Cramer, G. \& Fait, A. (2014). Metabolite and transcript profiling of berry skin during fruit development elucidates differential regulation between Cabernet Sauvignon and Shiraz cultivars at branching points in the polyphenol pathway. BMC Plant Biology. 14, 188 https://doi.org/10.1186/s12870-014-0188-4 